\title{
Strategic Display and Response to Emotions: Developing Evidence-based Negotiation Expertise in Emotion Management (NEEM)
}

\author{
Georges Potworowski and Shirli Kopelman
}

Ross School of Business, University of Michigan, Ann Arbor, MI, USA

\author{
Keywords \\ negotiation, emotion, decision \\ making, expertise, teaching.

\section{Correspondence} \\ Georges Potworowski, Ross \\ School of Business, University of \\ Michigan, Ann Arbor, Ml 48109- \\ 1234, USA; \\ e-mail: potwo@bus.umich.edu.
}

\begin{abstract}
This article conceptualizes emotion management as a form of negotiation expertise, and integrates the nascent empirical literature on emotion in negotiation with concepts from the learning sciences literature to suggest how negotiation expertise in emotion management (NEEM) can be taught. We argue that NEEM differs from emotional intelligence in fundamental ways, and that it consists of sensitivity to strategically relevant emotional cues, ability to strategically display and respond to emotions in negotiations, and the inclination to manage emotions for superior objective and subjective negotiation performance. We propose a method of developing NEEM in the classroom and identify directions for future research.
\end{abstract}

A growing body of research that investigates the influence of emotions on negotiation processes and outcomes (for a review, see Barry, Fulmer, \& Goates, 2006; Li \& Roloff, 2006) suggests that the ability to manage emotions before, during, and following a negotiation is an important negotiation skill. Whether emotions that surface in a negotiation are integral to the task or carried over from prior events (Lerner \& Keltner, 2000), negotiators inevitably encounter their own felt and displayed emotions, as well as emotions displayed by their counterparts. We suggest that emotion management is a domain of expertise that allows negotiators to leverage the benefits of emotions and avoid their potential pitfalls. A negotiator may want to leverage emotions because they can serve as sources of strategic information (e.g., Forgas, 2001; Van Kleef, De Dreu, \& Manstead, 2004a) and influence (e.g., Barry, 1999; Forgas, 2001; Kopelman, Rosette, \& Thompson, 2006). We propose that emotion management in negotiations, or the leveraging of

We thank Jeanne M. Brett, Richard J. Vath, and three anonymous reviewers for their insightful and constructive contributions to this article. 
emotions through strategic display of one's own emotions (Barry, 1999; Frank, 1988; Kopelman et al., 2006) and strategic response to emotions displayed by others (Kopelman, Gewurz, \& Sacharin, 2008), is a skill that can be taught. In this article, we conceptualize emotion management in negotiation as a form of expertise, review relevant research, identify gaps in the current state of knowledge on emotion management in negotiations, and propose a method of developing such expertise in a classroom setting.

\section{Negotiation Expertise in Emotion Management}

We conceptualize emotion management as a form of expertise. Expertise is defined as reproducible superior performance in a given domain (Ericsson, Krampe, \& Tesch-Römer, 1993). Expertise in emotion management in negotiations entails leveraging one's own and the other party's emotions to maximize absolute economic outcomes, subjective evaluation of relative outcomes (Loewenstein, Thompson, \& Bazerman, 1989; Messick \& Sentis, 1985), and subjective social perceptions not only of instrumental outcomes, but also of feelings about the self, feelings about the negotiation process, and feelings about the relationship (Curhan, Elfenbein, \& Xu, 2006).

Negotiation Expertise in Emotion Management (NEEM) differs qualitatively from models of emotional intelligences (EI) that are trait-based (e.g., Petrides \& Furnham, 2001) or have trait components (e.g., Goleman, 1995). It does so because a fundamental assumption of NEEM is that domain-specific emotion management is learned and, in principle, teachable. NEEM is more closely related to ability-based EI (e.g., Mayer \& Salovey, 1997; see Petrides \& Furnham, 2000, for more on the distinction between types of EI) in that NEEM is similar to Mayer and Salovey's four ability branches of EI (the ability to perceive emotions accurately, use emotion to facilitate thought, understand emotion, and manage emotions). However, NEEM differs from ability-based EI in that (a) it is domain-specific, (b) its sensitivities and abilities develop from and do not merely use domain-specific knowledge, (c) it can be learned, but takes significant time and effort to do so, and finally, (d) it has a motivational component.

First, whereas EI is a general ability, NEEM is a domain-specific form of consistent superior performance. Mayer, Salovey, and Caruso (2004) cite Sternberg, Weschler, and others in characterizing intelligence as "primarily a capacity to carry out abstract thought, as well as the general ability to learn and adapt to the environment" (p. 198). Expertise, in contrast, is fundamentally grounded in a constrained content domain, and thus is not a general ability. Expertise may transfer to closely related tasks, though the further the task is from the domain, the less relevant is the expertise. Although the acquisition of NEEM would almost certainly be facilitated (and accelerated) by high trait or ability-based EI, to conflate NEEM and EI would be to ignore over 60 years of expertise literature that grew out of de Groot's (1965) seminal work in the 1940s showing expert performance cannot be explained by intelligence or general problemsolving ability.

Second, whereas EI is a stable aptitude that draws on knowledge, in NEEM domain knowledge leads to the development and refinement of domain-specific sensitivities and 
abilities. Mayer et al. (2004) point out that "EI is a relatively stable aptitude, whereas emotional knowledge - the kind of emotional information that emotional intelligence operates on-is relatively easy to acquire and teach" (p. 209). Although NEEM too relies on emotional knowledge, this knowledge is not "operated" on by a stable aptitude. Instead, knowledge leads to the development of domain-specific pattern recognition and problem-solving strategies.

Third, in contrast to Mayer, Salovey, and Caruso's claim that emotional knowledge is easy to acquire and teach, expertise takes time to develop. The degree of knowledge acquisition, consolidation, and integration needed to develop the kind of sensitivities and abilities required for expert performance typically involves at least 10 years of deliberate practice, or pushing the limits of one's knowledge and performance (Ericsson et al., 1993). Clearly, students cannot be expected to become expert negotiators after a semester-long course. However, they can begin to develop their expertise (Dreyfus \& Dreyfus, 1986). We later propose an effective teaching approach that both establishes in students the core knowledge and dispositions of NEEM, and also helps instill in them the disposition for deliberate practice.

Finally, deliberate practice involves motivation (see Hatano \& Inagaki, 1986, on two types of expert learning motivation). In contrast, EI does not include a motivational component. In fact, the inclination to use one's general intelligence has been found to be distinct from intelligence itself (e.g., Stanovich \& West, 2000), suggesting that the same might be true of emotional intelligence. Ultimately, the difference between an intelligence and an expertise can be illustrated by what it takes to perform a surgery. To become a surgeon, an individual must be intelligent (in addition to having other qualities). However, a surgeon's performance does not boil down to her intelligence: Without the domain-specific knowledge, sensitivities, and abilities developed through years of deliberate practice, she could not perform a complex surgery successfully.

These distinguishing characteristics of NEEM suggest that it is not so vulnerable to the criticisms levied against EI, such as being too broad and vague a construct to be meaningful (Locke, 2005), measuring knowledge of emotion, not actual performance (Brody, 2004), or simply indicating conformity to a cultural standard. Moreover, the few studies that examined the role EI on negotiation outcomes have not been encouraging. Using a unidimensional measure of EI, Foo, Elfenbein, Tan, and Aik (2004) found that EI was related to greater integrative performance in a negotiation, but lower distributive performance, suggesting that negotiators high in EI were agreeable and able to create value, but less able to claim it. This is partly echoed in Mueller and Curhan (2006), who used Mayer, Salovey, and Caruso's (2002) multi-dimensional measure of EI and found that only a negotiator's understanding of emotion was related to her counterpart's postnegotiation positive mood, outcome satisfaction, liking the negotiator, and being willing to negotiate with her again. These findings suggest that EI is like general intelligence and problem-solving ability in that it does not account for expert performance.

We define NEEM along four core dimensions: knowledge, sensitivities, abilities, and inclinations. Beyond the basic domain-specific knowledge that is the foundation of any expertise, we draw on Perkins, Jay, and Tishman's (1993) concept of disposition-the 
tendency to deliberately engage in effective practices-as a framework to characterize the components of NEEM. The three elements of disposition are sensitivity, ability, and inclination. Sensitivity is a relatively automatic, perception-like pattern recognition that cues a given beneficial practice (e.g., noticing the emotional displays of the other negotiator that convey strategic information). The sensitivity of NEEM goes beyond the mere recognition of emotions to noticing contextually embedded emotions that are salient to maximizing utility at a given point in a negotiation. Thus, it is one thing to recognize anxiety in general, but quite another to integrate that basic recognition with domain knowledge to see the possible causes and strategic significance of anxiety at different stages of a negotiation. Second, ability is the capacity to execute a given practice (e.g., alleviating a counterpart's anxiety in different ways), and not merely the capacity to describe how to execute it. Finally, inclination is the tendency to consistently execute a practice (e.g., overcoming one's anxiety about anchoring; Rosette \& Kopelman, 2008).

Taken together, sensitivity directs an expert's perception, ability gives her the capacity to consistently achieve superior performance, and inclination is what drives the expert to do so and to continue to improve (i.e., learn) over time. Next, we draw on research findings in the negotiation and emotion literatures to suggest a few examples of sensitivities and abilities important to NEEM. The inclination to use these will depend in part on how their development is encouraged in the classroom, which we treat in the subsequent section on teaching NEEM.

\section{NEEM Sensitivities}

Key emotion management sensitivities in negotiations include, but are not limited to: (a) awareness that emotions are present at different stages of the negotiation and related to specific strategies, (b) identification of discrete emotions as they occur during a negotiation, and (c) gauging the intensity of a felt or displayed emotion. Research suggests that people across cultures experience, display, and recognize six basic emotions: anger, disgust, fear, sadness, surprise, and happiness (Ekman, Friesen, \& Ellsworth, 1972), and that, whether positive or negative, emotions vary in intensity (Barrett \& Russell, 1998; Larsen \& Diener, 1992). In contrast to enduring mood, which is considered a diffuse psychological state, emotion is defined as a short-lived differentiated affective response to a specific situation (e.g., Barry, 1999; Schwarz \& Clore, 1996). Emotions are either triggered by an identifiable event or brought on as a means to achieving an aspired end. According to appraisal theories (e.g., Frijda, 1986; Roseman, 1984; Scherer, 1984; Smith \& Ellsworth, 1985), emotions result from immediate evaluations of a given situation.

Identifying one's own emotions may come naturally to some negotiators, whereas others may need to develop this sensitivity. Identifying emotions actually felt by the other party is usually more challenging because the other negotiator may attempt to conceal these emotions. Furthermore, one's own emotional state can influence the perception of others' emotions. For example, sad people will identify sadness-congruent words faster and will perceive arguments with a sad tone as more persuasive than arguments with an angry tone, because sad emotions are congruent with their current personal reality (Niedenthal, Halberstadt, \& Setterlund, 1997). Thus, identification of 
discrete emotions is fundamental, but not enough. One also benefits from a sensitivity to the influence of one's own emotions on one's perception of the other parties' emotions, as well as a sensitivity to when negotiation events elicit specific emotions. Likewise, a negotiator would benefit from a sensitivity to anticipate how the other party may interpret her own emotional display.

A negotiator should benefit from being aware of emotions, identifying his own and others' emotions, and gauging the intensity of these emotions because emotions in negotiations convey relevant information (e.g., Forgas, 2001; Van Kleef, De Dreu, \& Manstead, 2004b) and can strategically influence behavior (e.g., Barry, 1999; Forgas, 2001; Kopelman et al., 2006). These sensitivities build the foundation of emotion management; without these emotion management sensitivities there would be no cues to guide the use of emotional management abilities.

\section{NEEM Abilities}

We conceptualize three types of NEEM abilities: (1) attribution of recognized emotions, (2) strategic display of emotions, and (3) strategic response to displayed emotions.

\section{Attribution of Recognized Emotions}

The emotion as social information model (EASI; Van Kleef et al., 2004b) suggests that emotions serve an important role because they communicate information about strategic elements of the negotiation. Furthermore, emotions also convey important information about how a negotiator thinks. Emotions can be differentiated along several appraisal dimensions, such as responsibility, control, and urgency. For example, anger and happiness differ with regard to who is held responsible for the situation, how much personal control is felt, and whether the experience includes a sense of urgency to act (Ellsworth \& Scherer, 2003), which have consequences for strategic choices in negotiations. It is also important to appraise whether the emotion felt or expressed during the negotiating process is integral to the given negotiation task or incidental; emotions may be carried over from an unrelated event to the current negotiation situation (Lerner \& Keltner, 2000). For example, if anger is incidental to the negotiation, it would not necessarily communicate information about a negotiator's satisfaction with the level of concessions on price, even though it could be misconstrued as doing so. On the other hand, incidental anger would communicate relevant relational information about the state of mind of the angry party, which, while also salient, requires a different course of action.

Research provides insights about how unmanaged emotions tend to influence negotiators, as well as the negotiation process. For example, angry people have a tendency to blame others (Quigley \& Tedeschi, 1996) and are likely to attribute higher responsibility to other parties when situations are ambiguous and open to interpretation (Keltner, Ellsworth, \& Edwards, 1993). Furthermore, angry people are likely to have a strong desire to take action against others (Mackie, Devos, \& Smith, 2000), which may lead them to take punitive actions against those who may not be the source of their anger (Goldberg, Lerner, \& Tetlock, 1999; Lerner, Goldberg, \& Tetlock, 1998). 
In contrast, happy people are likely to feel relatively certain about the course of events, for example, during the negotiation process, and feel in control, and thus more likely to assume personal responsibility for the outcome (Ellsworth \& Scherer, 2003). Thus, with respect to appraisals of control and to some extent certainty, a happy person and an angry person would be expected to behave similarly. A happy person differs from an angry person, however, in her tendency to take action in that she would not be likely to attribute responsibility of the situation to others and may therefore sense little urgency for change. Happy people are also less likely to take high risks (Isen \& Patrick, 1983), whereas angry people are more likely to engage in risk-seeking choices (Lerner \& Keltner, 2001), have a tendency to behave optimistically about the likelihood of future positive events, and perceive less risk of future negative events (Lerner, Gonzalez, Small, \& Fischhoff, 2003; Lerner \& Keltner, 2000). Finally, although a happy person is likely to experience less urgency to act, a happy person is more likely to engage in prosocial helping behavior (Batson, 1990; Batson, Coke, Chard, Smith, \& Taliaferro, 1979). This may lead happy negotiators to be perceived as more trustworthy. Indeed, others view angry negotiators as less trustworthy than those who are happy or sad (Dunn \& Schweitzer, 2005). Clearly, research is still needed to determine how such emotional dynamics play out in negotiations.

Some of the above attributions of emotions occur automatically, and even some experienced negotiators may be unaware of them. To effectively manage emotions in negotiations would therefore require a better understanding of what attributions and tendencies are likely to occur if emotional dynamics are allowed to play out. Active intervention may be necessary to leverage these attributions strategically. For example, "I realize that I'm angry and have an urgency to act immediately, but I will hold myself back and wait until tomorrow to make a decision." At the very least, a negotiator will benefit from being aware of the dynamics that take place. For example, "I really want to make the decision now, and that's probably because I'm angry and have an urgency to act."

\section{Strategic Display of Emotion}

The strategic display of one's own emotion is an important emotion management ability that may involve a conscious decision about whether and how to express a genuinely felt emotion, or feign (i.e., generate, amplify, or suppress) a desired emotion as a source of influence (e.g., Barry, 1999; Forgas, 2001; Kopelman et al., 2006). For example, toward the end of the negotiation, a negotiator who is pleased with the outcome is likely to feel happy. Mindlessly expressing this genuine happiness can have beneficial or damaging consequences. If a negotiator's happiness is attributed by her counterpart to the successful joint effort to create value in the current negotiation, it may set the stage for a productive future business relationship (Kopelman et al., 2006). In contrast, if the counterpart interprets this expression of happiness through a distributive mindset, it may signal to her that he made too many concessions (i.e., if she is happy, she got the better deal and I lost). Worse still, if the expression of happiness is interpreted as gloating, it may damage the long-term relationship (Thompson, Valley, \& Kramer, 1995). Thus, by strategically choosing whether and how to display genuinely felt emotions of 
happiness at the end of the negotiation, the negotiator can protect herself against disadvantageous attributions of her emotions.

It can also be a strategic choice to feign an emotion, that is convincingly generate and display an emotion that would not have otherwise been felt at that moment. For example, even if a negotiator is not happy at the onset of a negotiation, it may be beneficial to feign happiness. To elicit a convincing display of happiness, a negotiator could focus on an intrinsic or extrinsic idea that leads her to feel genuinely happy at that moment, and express this happiness with regards to the opportunity to work together and explore joint gains.

In sum, one mark of emotion management expertise is the ability of a negotiator to consciously adjust her emotional display to serve her objectives. One way to do this is by amplifying or suppressing an authentically experienced emotion. Another way is to feign a strategically advantageous positive or negative emotion (Hochschild, 1983; Rafaeli \& Sutton, 1991). Whether authentic or feigned, strategically displayed emotions can function as behavioral persuasion tactics that lead to desired outcomes. For example, display of anger can be financially advantageous to a negotiator with high power, since others are likely to concede to his or her demands (Sinaceur \& Tiedens, 2006; Van Kleef et al., 2004a). Although in situations such as power asymmetry, low information, or under the operation of an agreement bias, displaying discontent and anger (e.g., pounding one's fist on the table) leads the other party to make concessions during the negotiating process (e.g., Rafaeli \& Sutton, 1991; Sinaceur \& Neale, 2005; Van Kleef et al., 2004a), it also can boomerang. Under certain conditions, anger may lead to a conflict spiral. The other party might react by also feeling and displaying anger (Barsade, 2002; Hareli \& Rafaeli, 2008; Hatfield, Cacioppo, \& Rapson, 1992), and angry negotiators are more likely to use competitive strategies (Forgas, 1998) and over-retaliate (Allred, 1999; Daly, 1991). Displaying anger in cultures such as the U.S. and East Asia reduces the likelihood that one's offer will be accepted by increasing the likelihood of a spiteful response by the other party (e.g., Kopelman \& Rosette, 2008; Kopelman et al., 2006; Pillutla \& Murnighan, 1996), and thus may lead to a negotiation impasse (Friedman et al., 2004).

In contrast, strategic display of positive emotion, such as happiness, facilitates the development of reciprocal long-term relationships in potentially integrative settings (Kopelman et al., 2006), and in East Asian cultures tends to increase the likelihood of closing a favorable deal in distributive settings (Kopelman \& Rosette, 2008). In general, happy negotiators are more likely to share information and have an increased preference for and adoption of cooperative negotiation strategies (Baron, 1990; Forgas, 1998) that lead to value creation and better joint outcomes (Carnevale \& Isen, 1986).

\section{Strategic Response to Displayed Emotion}

Strategically choosing one's own response to the emotions displayed by the other party is also an important emotion management ability (Kopelman et al., 2008). When considering the emotions of the other party, a negotiator may begin by assessing whether or not they are authentic. Emotions are considered authentic when internally experienced and externally displayed emotions align (Côté, 2005). 
Despite the fact that there has been relatively little empirical testing, experienced mediators and skilled negotiators have found some strategic responses to be useful for managing emotionally charged negotiations. Strategic responses such as venting (e.g., Lewicki, Saunders, \& Minton, 1999) and cooling-off periods (e.g., Ury, 1993; Ury, Brett, \& Goldberg, 1988), as well as addressing the core concerns of the emotional party (Fisher \& Shapiro, 2005) are believed to help overcome negative emotion. This, in turn, leads to more collaborative and successful win-win negotiated outcomes, and directs positive emotion toward constructive information exchange and mutually beneficial outcomes (Kopelman et al., 2008). Gottman and DeClaire's (2001) work on building better relationships seems especially salient, and future research could examine whether exercises they suggest (e.g., the emotional communication game) could be adapted to benefit negotiators. Likewise, future research should examine the effectiveness of the recommendations Adler, Rosen, and Silverstein (1998) make on how to deal with one's own and other's anger and fear-the two most potent emotions confronting negotiators, they argue.

The basic assumption in the nonempirical negotiation literature is that only negative emotion is problematic and serves as an obstacle to successful negotiations (Kopelman et al., 2008). The literature indirectly suggests that positive emotion would always signal that the underlying concerns of the other party have been addressed. In terms of Fisher and Shapiro's (2005) elements of emotion, expressed happiness would indicate that affiliation had been properly established, autonomy respected, status acknowledged, and a fulfilling role had been chosen. Cooperation and beneficial agreements would then be expected to ensue. However, empirical research on decision making in negotiation settings suggests that in some situations where these core concerns are met, such as when negotiating in the context of close relationships (McGinn, 2006), negotiators may be less focused on expanding the pie because they are focused more on dividing resources equally (Messick, 1993; Thompson \& DeHarpport, 1998). Their need to avoid relationship conflict (Jehn, 1995) may lead them to make nonstrategic concessions and miss opportunities to discover differences in priorities that could be leveraged to expand the pie. In the end, positive emotions not only can present obstacles for optimal economic outcomes, but their effects may be especially difficult to manage because positive emotions are an intrinsically desirable state.

Ultimately, NEEM involves the ability to distinguish between situations where positive and negative emotions displayed by the other party are beneficial, detrimental, or irrelevant, to the negotiator's utility. This would inform the negotiator's choice of a strategic response that could better harness and perhaps amplify the other party's emotion or, in contrast, attempt to dispel and overcome the obstacles the other party's emotion presents. Once a negotiator assesses whether a strategic response would harness or dispel the other party's emotions, an appropriate behavioral response (e.g., ignoring their emotion, allowing them to vent, confronting them) can be adopted.

\section{Teaching NEEM}

To learn to manage emotions in negotiations, students need to experience emotions in the context of negotiations. Rather than focus solely on how to charge classroom negoti- 
ations with more emotion, we propose a principled, theory-driven, and evidence-based approach to developing emotion management expertise. If all three elements (sensitivities, abilities, and inclinations) are built into a negotiation course, students are less likely to leave with inert knowledge, and more likely to change their negotiation practice to bridge what Pfeffer and Sutton (2000) call the "knowing-doing gap." The upshot is that the extent to which a course incorporates a learning process that accelerates the development of negotiation dispositions, it accelerates the development of negotiation expertise in emotion management.

Helping students of negotiation develop the fundamentals of NEEM rests on the assumption that, at the very least, emotion management sensitivities and abilities can be improved, and that the inclination to use them takes root within the timeframe of a course. However, for students to continue to develop their NEEM they would need to leave a course with a second disposition: to learn from the negotiations they experience outside the classroom. This second, self-directed learning disposition is the key to keeping emotion management inclinations labile enough so that, through deliberate practice, students can continue to adjust and refine their emotion management sensitivities and abilities following the negotiation course. The disposition to continue learning is especially important because managers are increasingly changing jobs, as well as being asked to negotiate in multi-cultural contexts where the sensitivities and abilities that are functional in one's own culture may be dysfunctional in another. Given that negotiation is fundamental to effective management, it is one domain where the call for evidencebased practice in management (Rousseau, 2006; Rousseau \& McCarthy, 2007) can most easily be answered.

Our approach to teaching NEEM is based on a system that integrates key principles of current educational theory to make learning more effective. Effective emotion management learning results in the development of NEEM through (a) heightened and more contextually discriminating sensitivities, (b) consistently superior execution of emotion management abilities, and (c) the inclination (i.e., the habit) of executing these abilities in practice. Moreover, the use of this approach also structures and encourages increasingly self-directed learning, thus developing students' disposition to continue the development of their NEEM through reflective practice following the course. The approach centers on a deliberately cyclical learning structure (see Bransford, Brown, \& Cocking, 1999; Potworowski, Vath, \& Shah, 2006), in contrast to the traditionally linear approaches

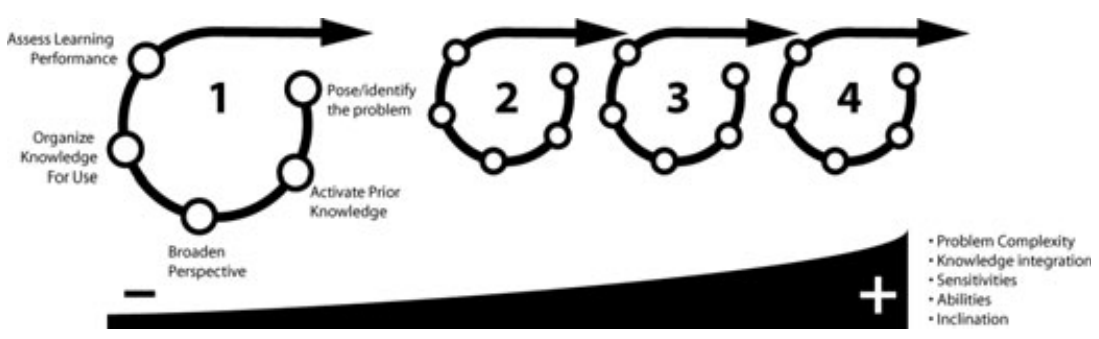

Figure 1. The learning cycle and changes across cycles. 
to learning that may have incidental cyclical components (Nadler, Thompson, \& van Boven, 2003). The cyclical learning structure (see Figure 1) follows five steps: (a) introduction of the problem, (b) activation of prior knowledge, (c) broadening of perspective, (d) organizing knowledge for use, and (e) assessing learning performance.

In cyclical learning, the focal sensitivities and abilities introduced and practiced in one cycle are systematically developed, refined, and combined with others in subsequent cycles. In principle, with each cycle students' knowledge becomes richer and more integrated, their sensitivities become more refined, their abilities develop, and their inclination to manage emotions is further reinforced. The opportunities to experience, practice, reflect on, and develop sensitivities and abilities are most beneficial when they arise in varied (Lowenstein, Thompson, \& Genter, 2003) and increasingly challenging contexts. Thus, as students' NEEM develops, their growing capacity to deal with and learn from more complex, subtle, and varied negotiation contexts is challenged at each cycle with developmentally appropriate problems. Meanwhile, they internalize the cycle as the way to systematically learn from negotiations, and in so doing become better prepared to leverage their negotiations experiences outside the classroom to further develop their expertise (Bransford \& Schwartz, 1999).

To begin the emotion management learning cycle, emotional sensitivities can be highlighted as early as the introductory session of a negotiation course. Highlighting emotion sensitivities alongside the core teaching of negotiation strategy will attune students to the role emotions can play in negotiations. The cycle could begin, for example, with a simple distributive negotiation where one of the key lessons learned is the value of anchoring with the first offer. The first step of the cycle can be incorporated into the negotiation debrief by posing the following problem to students: Should you make the first offer? Why or why not? Note that by asking for justification, the ensuing discussion will naturally lead to the second part of the cycle as students activate prior knowledge, beliefs, and experiences. The instructor can then highlight the emotional component (i.e., anxiety about making the first offer) and can guide students in exploring whether they felt anxious, what cues, if any, they perceived about their counterpart's emotion, and what they did about it.

After discussing cues that indicate anxiety (e.g., beating around the bush), the instructor can highlight research findings showing that individuals who make the first offer experience increased anxiety that leads to decreased satisfaction with the negotiation, which sours the higher economic returns of this strategy (Rosette \& Kopelman, 2008). This can help motivate the need to develop the ability to strategically respond to anchoring anxiety. To broaden students' perspectives on the problem, one can then either capitalize on differing opinions about whether and how to deal with anchoring anxiety (e.g., visualization of anchoring beforehand, practicing making first offers, exploring reasons for one's anxiety, taking a deep breath; research is needed to confirm whether these methods are effective in this context) and note empirical findings that show that an objective benchmark for the financial value of the first offer reduces anxiety (Rosette \& Kopelman, 2008). To move from multiple perspectives to the fourth stage, organizing knowledge for use, the different perspectives can be listed and their costs, benefits, effectiveness, and contextual relevance explicitly compared. The discus- 
sion can then shift to a more prescriptive phase. Note the same pattern can be followed in parallel to address other emotional outcomes of anchoring, such as responding to outrageous first offers (e.g., to help save face and get the negotiation on track), or avoiding the winner's curse.

The various emotions and their respective appropriate strategic responses can be integrated around the anchoring "event," making it an "emotions by event" organization of knowledge for use. Although one can also organize "events by emotion" (e.g., all the negotiation-related events when one can experience anxiety), emotions lack the narrative structure of series of events, and would thus make the learning less memorable. That said, it is worth helping students develop a rich network of associations, and one can do so by connecting previous lessons (e.g., "how does this relate to what we learned about dealing with anxiety about anchoring?"). Finally, assessing learning performance can come in the form of written self-reflections for homework and anchoring behavior in the next cycle.

In addition to actual negotiation simulations, one can teach NEEM by providing explicit models. For example, one could approach teaching strategic response to emotion in negotiation by showing a clip from a relatively short video of a negotiation (e.g., Kaufer \& Kellman, 1991) in which the negotiators display subtle, but potentially consequential, emotions. One could then ask the class an open-ended question about what they noticed in this exchange. After eliciting from students a list of attributes they noticed, one could ask what an expert should be looking for or noticing about the emotions, and why. This would give the instructor a sense of what students believe they should be noticing in a negotiation, and consequently an idea of what questions to ask to steer the discussion and lesson so students' beliefs are made more accurate. The instructor can then open up a discussion by asking specific questions about the emotional states of the negotiators, including, for example, cues that indicated specific emotions. The exercise can be taken a step further by running the next segment of the video and stopping just before one of the parties engages an emotion management response tactic. One can then ask students a "what now?" question to start a discussion about how and why they would respond to the emotions in a particular way. Finally, one could broaden perspectives by following up on student responses to the "what now?" question with "what if" questions to explore potential consequences of proposed actions and slightly different scenarios. By pointing to relevant research, the instructor can then help students organize evidence-based knowledge for strategic use.

To assess performance, one could use a second video clip (e.g., from a movie, a video of an actual negotiation, or one created for the purpose), and at one point hand out roles that mirror those in the video. Students would then role-play the next step in the negotiation. This type of exercise has several benefits. First, it can help each student see some of her own emotion management strengths and weaknesses, as well as those of her peers. This is not only valuable information to help individualize the course, but it also helps students identify who in the classroom-ideally structured as a community of practice (Brown \& Duguid, 1991; Lave \& Wenger, 1991)—can help them improve specific sensitivities and abilities. Second, in a diverse classroom, the range of sensitivities and proposed strategic responses to emotions can also broaden perspectives by revealing in concrete ways individual, gender, and cultural variations. Finally, the instructor can 
use the exercise as the first in a number of experiences that illustrate the importance of being able to understand who your counterpart is and adapt to him. This involves a conceptual change from thinking of oneself as (desiring to be) a specific and narrow kind of negotiator (e.g., tough and uncompromising), to thinking of oneself as a flexible negotiator who is sensitive to a counterpart's emotions and capable of accommodating him to one's advantage or the advantage of both parties.

As students begin to understand what makes them feel a certain way in a negotiation, why, and what can be done, they can begin to consider the emotions of their counterparts. By explicitly considering emotions through perspective taking over the course of several cycles, students will become increasingly sensitive to what makes their counterparts feel anxious in negotiations (e.g., how they can anticipate or behaviorally identify other parties' anxiety, understand why counterparts are anxious, and what can be done). The same is true, of course, for any other emotion, though, given the limited time allotted to teaching NEEM, the instructor may want to focus on counter-intuitive findings (e.g., some of the potential disadvantages of happiness). Finally, to help students integrate the different clusters of organized knowledge produced over the course of several learning cycles, students can be asked to build an inventory of strategic responses to different emotions (e.g., as part of a final assignment). Such an inventory could consist of a list of their own felt and displayed emotions, the assessment of other's felt and displayed emotions, and their potential causes, assessment tactics, and actions.

Students can learn to display emotions strategically in a number of ways. One approach is to use a simulation in which they are coached to intentionally display emotions. Such a simulation would allow students to see their own and each others' (naïve) beliefs, and how (under)developed their sensitivities and abilities might be. Research suggests that negotiators can express a desired emotion and that the behavioral display of the emotion, like other strategies in their negotiation tool kit, may serve as a means to attain a desired outcome (Kopelman et al., 2006). Deliberate regulation of emotion may involve different levels of acting (Côté, 2005; Grandey, 2000; Gross, 1998; Hochschild, 1983). In deep acting, internally experienced and externally displayed emotions are aligned and therefore considered authentic. At other times, however, the negotiator's emotional strategy may be at odds with how he or she feels at that moment. This type of emotional regulation is called surface acting, and because it influences only the display of emotion, not the internal experience of emotion, it is considered to be inauthentic (Côté, 2005). Whether the strategic behavioral display of emotion represents emotions psychologically experienced at that moment (i.e., the negotiator strategically "harnesses felt emotions," perhaps exaggerating them as he displays them) or whether it represents deliberately feigned emotion (i.e., the negotiator "wears an emotional mask," hiding her current feelings), some negotiators can intentionally adjust their emotional display in a desired direction by either amplifying or suppressing their own experienced emotion (Hochschild, 1983; Levenson, 1994).

Adopting a coaching manipulation that consisted of a page of expert advice on why it would be advantageous to display a particular emotion throughout the negation, Kopelman et al. (2006) confirmed that it is even possible for novice negotiators (e.g., MBA students) to convincingly display positive and negative, in contrast to neutral, emotions 
in a socially interactive face-to-face negotiation simulation. This coaching technique was replicated and extended to anger by Sinaceur and Tiedens (2006) and thus offers a viable strategy for producing emotional interactions in classroom settings. This research suggests that the strategic display of positive or negative emotions by one negotiator led to the emergence of positive or negative emotional contagion. Interestingly, whether the degree of the displayed emotion was accurately judged by the other party was contingent on the emotion displayed. When negotiators displayed positive emotion, the opposing party accurately judged the emotional display as positive-that is, there was congruence between what the target negotiator believed she displayed and what the focal negotiator judged; however, when negotiators displayed generally negative emotion the negotiator believed she was more negative than judged by the opposing party (Kopelman et al., 2006). This suggests that when negotiators strategically choose to display negative emotion they may be likely to overestimate how others perceive the intensity of that emotion. Alternatively, they may be overconfident in their ability to display negative emotion, perhaps experiencing more emotion than they actually displayed, which would be consistent with research that showed that experienced negative emotions were related to expression only for people with dispositionally high expressivity (Gross, John, \& Richards, 2000) and suggests that negative emotion may be relatively difficult to feign. More research is needed to understand the factors influencing the perception of emotional intensity.

\section{Ethical Considerations of NEEM}

It is important to recognize that NEEM, especially the strategic display of emotion, can involve deception. Two earlier examples-displaying anger to try to gain concessions and suppressing incidental frustration and displaying happiness to help encourage positive rapport and the creation of mutual gains-illustrate this well. Deception, or intentionally misleading one's counterpart, raises ethical questions-ones that many teachers of negotiation believe are important to discuss in class (Lewicki, 1983). It is clear that NEEM can be abused for illegal and unethical ends; however, being incapable of emotion management is also costly. We propose that using the learning cycle to teach NEEM includes raising students' awareness and experience of the ethics of deception. Ultimately, students will apply their NEEM in a way that resonates with their values. If the instructor integrates the discussion of the ethics of deception into the learning cycle, then students will be more sensitive to the legal, practical (e.g., reputational), and ethical ramifications of engaging in deception.

Following the learning cycle to discuss the ethics of deception might unfold as follows. First, pose the problem-when and how is it acceptable to deceive (with emotions) in a negotiation? This might arise naturally while teaching dispute resolution. One might explore students' prior knowledge and beliefs about emotional deception and get them to generate a variety of criteria to judge whether a legal act of deception is ethically acceptable or not. These might include religious or philosophical positions that make prescriptions (e.g., utilitarianism), or involve mental simulations, such as imagining the consequences of having one's deceptive act described in a newspaper 
(Lax \& Sebenius, 1986). These criteria can serve as a good starting point for a discussion to broaden perspectives on the ethics of deception, which should raise important questions about the boundary conditions of what counts as deception. For example, does the strategic display of a generated emotion count as an act of deception? Can the end (e.g., better relationship) justify emotional deception as the means? To help students organize knowledge for use, one might turn to Robinson, Lewicki, and Donahue's (2000) typology of deception. Alternatively, Shell's (2007) chapter on the different schools of bargaining ethics (i.e., poker, idealist, and pragmatist) can help students discover with which, if any, school they identify, and the corresponding conditions under which the strategic display of emotion would be acceptable. One way to test learning at some later time in the class might involve seeing how thoughtfully students respond to hypothetical vignettes involving strategic emotional display.

\section{Conclusion}

We conceptualized negotiation expertise in emotion management (NEEM) and illustrated how it can be taught in the context of a negotiation course. We reviewed the empirical research on beneficial and detrimental influence of emotions on the negotiation process and outcomes with respect to the development of NEEM. We proposed that enabling students to develop and apply emotion management sensitivities and abilities in a safe learning environment will encourage the development of inclinations to apply them in negotiations and to continue to develop their NEEM beyond the classroom. To build NEEM, we suggested a learning cycle that involves a systematic way of posing problems, and expanding student understanding through simulations and exercises. We encouraged evidence-based discussions of the effects of emotions in negotiations, the value of emotions as a source of strategic information, the impact of emotions as a behavioral influence tactic, and the advantages and risks of managing different emotions, including the ethical implications of doing so. We encourage not only empirical research on the gaps in our knowledge of the effects of emotions on negotiations, but also research on how emotions can be strategically managed in negotiations (e.g., Kopelman et al., 2006, 2008). To apply this research to the development of NEEM requires more and better teaching materials-ones that can enhance the effect of the learning cycle so that students of negotiation are well equipped to deal with both the economic elements of a negotiation and the intricacies of emotions that are integral to social interactions.

\section{References}

Adler, R. S., Rosen, B., \& Silverstein, E. M. (1998). Emotions in negotiations: How to manage fear and anger. Negotiation Journal, 14, 161-180.

Allred, K. (1999). Anger and retaliation: Toward an understanding of impassioned conflict in organizations. In R. J. Bies, R. J. Lewicki, \& B. H. Sheppard (Eds.), Research on negotiation in organizations (Vol. 7, pp. 27-58). Stamford, CT: JAI Press.

Baron, R. A. (1990). Environmentally induced positive affect: Its impact on self-efficacy, task performance, negotiation and conflict. Journal of Applied Social Psychology, 20, 368-384. 
Barrett, L. F., \& Russell, J. A. (1998). Independence and bipolarity in the structure of affect. Journal of Personality and Social Psychology, 74, 967-984.

Barry, B. (1999). The tactical use of emotion in negotiation. In R. J. Bies \& R. J. Lewicki (Eds.), Research on negotiation in organizations (Vol. 7, pp. 93-121). Stamford, CT: JAI Press.

Barry, B., Fulmer, I., \& Goates, N. (2006). Bargaining with feeling: Emotionality in and around negotiation. In L. L. Thompson (Ed.), Negotiation theory and research (pp. 99-127). Madison, CT: Psychosocial Press.

Barsade, S. G. (2002). The ripple effect: Emotional contagion and its influence on group behavior. Administrative Science Quarterly, 47, 644-675.

Batson, C. D. (1990). Affect and altruism. In B. S. Moore \& A. M. Isen (Eds.), Affect and social behavior (pp. 89-125). New York: Cambridge University Press.

Batson, C., Coke, J., Chard, F., Smith, D., \& Taliaferro, A. (1979). Generality of the glow of goodwill: Effects of mood on helping and information acquisition. Social Psychology Quarterly, 42, 176-179.

Bransford, J. D., Brown, A. L., \& Cocking, R. R. (Eds.). (1999). How people learn: Brain, mind, experience, and school. Washington, DC: National Academy Press.

Bransford, J. D., \& Schwartz, D. L. (1999). Rethinking transfer: A simple proposal with multiple implications. Review of Research in Education, 24, 61-100.

Brody, N. (2004). What cognitive intelligence is and what emotional intelligence is not. Psychological Inquiry, 15, 234-238.

Brown, J. S., \& Duguid, P. (1991). Organizational learning and communities of practice: Toward a unified view of working, learning and innovation. Organizational Science, 2, 40-57.

Carnevale, P. J., \& Isen, A. M. (1986). The influence of positive effect and visual access on the discovery of integrative solutions in bilateral negotiation. Organizational Behavior \& Human Decision Processes, 37, 1-13.

Côté, S. (2005). A social interaction model of the effects of emotion regulation on work strain. Academy of Management Review, 30, 509-530.

Curhan, J. R., Elfenbein, H. A., \& Xu, H. (2006). What do people value when they negotiate? Mapping the domain of subjective value in negotiation. Journal of Personality and Social Psychology, 91, 493-512.

Daly, J. (1991). The effects of anger on negotiations over mergers and acquisitions. Negotiation Journal, 7, 31-39.

Dreyfus, H., \& Dreyfus, S. (1986). Minds over machine: The power of human intuition and expertise in the era of the computer. New York: The Free Press.

Dunn, J., \& Schweitzer, M. (2005). Feeling and believing: The influence of emotion on trust. Journal of Personality and Social Psychology, 88, 736-748.

Ekman, P., Friesen, W., \& Ellsworth, P. (1972). Emotion in the human face: Guidelines for research and an integration of findings. Oxford, U.K.: Pergamon Press.

Ellsworth, P., \& Scherer, K. (2003). Appraisal processes in emotion. In R. J. Davidson, K. R. Scherer, \& H. Goldsmith (Eds.), Handbook of affective sciences (pp. 572-595). Oxford, U.K.: Oxford University Press.

Ericsson, K. A., Krampe, R. T., \& Tesch-Römer, C. (1993). The role of deliberate practice in the acquisition of expert performance. Psychological Review, 100, 363-406.

Fisher, R., \& Shapiro, D. (2005). Beyond reason: Using your emotions as you negotiate. New York: Viking Press. 
Foo, M. D., Elfenbein, H. A., Tan, H. H., \& Aik, V.C. (2004). Emotional intelligence and negotiation: The tension between creating and claiming value. International Journal of Conflict Management, 15, 411-429.

Forgas, J. (1998). On feeling good and getting your way: Mood effects on negotiator cognition and bargaining strategies. Journal of Personality and Social Psychology, 74, $565-577$.

Forgas, J. P. (2001). On being moody but influential: The role of affect in social influence strategies. In J. P. Forgas \& K. D. Williams (Eds.), Social influence: Direct and indirect processes (pp. 147-166). New York: Psychology Press.

Frank, R. H. (1988). Passions within reason: The strategic role of the emotions. New York: W. W. Norton.

Friedman, R., Anderson, C., Brett, J., Olekalns, M., Goates, N., \& Lisco, C. C. (2004). The positive and negative effects of anger on dispute resolution: Evidence from electronically mediated disputes. Journal of Applied Psychology, 89, 369-376.

Frijda, N. (1986). The emotions. New York: Cambridge University Press.

Goldberg, J., Lerner, J., \& Tetlock, P. (1999). Rage and reason: The psychology of the intuitive prosecutor. European Journal of Social Psychology, 29, 781-795.

Goleman, D. P. (1995). Emotional intelligence: Why it can matter more than IQ for character, health and lifelong achievement. New York: Bantam Books.

Gottman, J. M., \& DeClaire, J. (2001). The relationship cure: A five-step guide for building better connections with family, friends, and lovers. New York: Crown Publishers.

Grandey, A. A. (2000). Emotion regulation in the workplace: A new way to conceptualize emotional labour. Journal of Occupational Health Psychology, 5, 95-110.

de Groot, A. D. (1965). Thought and choice in chess. Amsterdam: Noord-Hollandsche Uitgeversmaatschappij.

Gross, J. J. (1998). Antecedent- and response-focused emotion regulation: Divergent consequences for experience, expression and physiology. Journal of Personality \& Social Psychology, $74,224-237$.

Gross, J. J., John, O. P., \& Richards, J. M. (2000). The dissociation of emotion expression from emotion experience: A personality perspective. Personality and Social Psychology Bulletin, 26, 712-726.

Hareli, S. \& Rafaeli, A. (2008). Emotion Cycles: On the social influence of emotion in organizations. Research in Organizational Behavior, 28, 35-59.

Hatano, G., \& Inagaki, K. (1986). Two courses of expertise. In H. A. H. Stevenson \& K. Hakuta (Eds.), Child development and education in Japan (pp. 262-272). New York: W. H. Freeman and Company.

Hatfield, E., Cacioppo, J. T., \& Rapson, R. L. (1992). Primitive emotional contagion. In M. S. Clark (Ed.), Emotion and social behavior: Review of personality and social psychology (pp. 151177). Newbury Park, CA: Sage.

Hochschild, A. R. (1983). The managed heart: Commercialization of human feeling. Berkeley: University of California Press.

Isen, A., \& Patrick, R. (1983). The effect of positive feelings on risk taking: When the chips are down. Organizational Behavior and Human Performance, 31, 194-202.

Jehn, K. (1995). A multimethod examination of the benefits and detriments of intragroup conflict. Administrative Science Quarterly, 40, 256-282. 
Kaufer, S. (Writer), \& Kellman, B. (Director). (1991). Contractions. E. Heisler \& D. Heline (Producers), Murphy Brown [Television series episode]. New York: CBS Broadcasting, Inc.

Keltner, D., Ellsworth, P., \& Edwards, K. (1993). Beyond simple pessimism: Effects of sadness and anger on social perception. Journal of Personality and Social Psychology, 64, 740-752.

Kopelman, S., Gewurz, I., \& Sacharin, V. (2008). The power of presence: Strategic responses to displayed emotions in negotiation. In N. M. Ashkanasy \& C. L. Cooper (Eds.), Research companion to emotions in organizations (pp. 405-420). Northampton, MA: Edward Elgar.

Kopelman, S., \& Rosette, A. (2008). Cultural variation in response to strategic display of emotions during negotiations. Group Decision Making and Negotiations, 17, 1.

Kopelman, S., Rosette, A. S., \& Thompson, L. (2006). The three faces of Eve: Strategic displays of positive, negative and neutral emotions in negotiations. Organizational Behavior and Human Decision Processes, 99, 81-101.

Larsen, R. J., \& Diener, E. (1992). Promises and problems with the circumplex model of emotion. In M. S. Clark (Ed.), Review of personality and social psychology: Emotion (pp. 25-59). Newbury Park, CA: Sage.

Lave, J., \& Wenger, E. (1991). Situated learning: Legitimate peripheral participation. Cambridge: Cambridge University Press.

Lax, D. A., \& Sebenius, J. K. (1986). The manager as negotiator. New York: Free Press.

Lerner, J., Goldberg, J., \& Tetlock, P. (1998). Sober second thought: The effects of accountability, anger, and authoritarianism on attributions of responsibility. Personality and Social Psychology Bulletin, 25, 563-574.

Lerner, J., Gonzalez, R., Small, D., \& Fischhoff, B. (2003). Effects of fear and anger on perceived risks of terrorism: A national field experiment. Psychological Science, 14, 144-150.

Lerner, J., \& Keltner, D. (2000). Beyond valence: Toward a model of emotion-specific influences on judgment and choice. Cognition and Emotion, 14, 473-493.

Lerner, J., \& Keltner, D. (2001). Fear, anger, and risk. Journal of Personality and Social Psychology, 81, 146-159.

Levenson, R. W. (1994). Emotion control: Variations and consequences. In P. Ekman \& R. J. Davidson (Eds.), The nature of emotion (pp. 273-279). New York: Oxford University Press. Lewicki, R. (1983). Lying and deception: A behavioral model. In M. H. Bazerman \& R. J. Lewicki (Eds.), Negotiating in Organizations (pp. 68-90). Beverly Hills, CA: Sage.

Lewicki, R., Saunders, D., \& Minton, J. (1999). Negotiation (3rd ed.). Boston: McGraw-Hill.

Li, S., \& Roloff, M. E. (2006). Strategic emotion in negotiation: Cognition, emotion, and culture. In G. Riva, M. T. Anguera, B. K. Widerhold \& F. Mantovani (Eds.), From communication to presence: Cognition, emotions and culture towards the ultimate communicative experience (pp. 166-185). Amsterdam: IOS Press.

Locke, E. A. (2005). Why emotional intelligence is an invalid concept. Journal of Organizational Behavior, 26, 425-431.

Loewenstein, G. F., Thompson, L., \& Bazerman, M. (1989). Social utility and decision making in interpersonal contexts. Journal of Personality and Social Psychology, 57, 426-441.

Lowenstein, J., Thompson, L., \& Genter, D. (2003). Analogical learning in negotiation teams: Comparing cases promotes learning and transfer. Academy of Management Learning \& Education, 2, 119-127.

Mackie, D., Devos, T., \& Smith, E. (2000). Intergroup emotions: Explaining offensive action tendencies in an intergroup context. Journal of Personality and Social Psychology, 79, 602-616. 
Mayer, J. D., \& Salovey, P. (1997). What is emotional intelligence? In P. Salovey \& D. Sluyter (Eds.), Emotional development and emotional intelligence: Educational applications (pp. 3-31). New York: Basic Books.

Mayer, J. D., Salovey, P., \& Caruso, D. R. (2002). Mayer-Salovey-Caruso Emotional Intelligence Test (MSCEIT) user's manual. Toronto, ON: MHS.

Mayer, J. D., Salovey, P., \& Caruso, D. R. (2004). Emotional intelligence: Theory, findings, and implications. Psychological Inquiry, 15, 197-215.

McGinn, K. (2006). Relationships and negotiations in context. In L. Thompson (Ed.), Negotiation theory and research (pp. 129-144). Madison, CT: Psychosocial Press.

Messick, D. (1993). Equality as a decision heuristic. In B. A. Mellers \& B. Jonathan (Eds.), Psychological perspectives on justice: Theory and applications (pp. 11-31). New York: Cambridge University Press.

Messick, D. M., \& Sentis, K. P. (1985). Estimating social and nonsocial utility functions from ordinal data. European Journal of Social Psychology, 15, 389-399.

Mueller, J. S., \& Curhan, J. R. (2006). Emotional intelligence and counterpart affect induction in a negotiation. International Journal of Conflict Management, 17, 110-128.

Nadler, J., Thompson, L., \& van Boven, L. (2003). Learning negotiation skills: Four models of knowledge creation and transfer. Management Science, 49, 529-540.

Niedenthal, P., Halberstadt, J., \& Setterlund, M. (1997). Being happy and seeing happy: Emotional state mediates visual word recognition. Cognition \& Emotion, 11, 403-432.

Perkins, D., Jay, E., \& Tishman, S. (1993). Beyond abilities: A dispositional theory of thinking. The Merrill-Palmer Quarterly, 39, 1-21.

Petrides, K. V., \& Furnham, A. (2000). On the dimensional structure of emotional intelligence. Personality and Individual Differences, 29, 313-320.

Petrides, K. V., \& Furnham, A. (2001). Trait emotional intelligence: Psychometric investigation with reference to established trait taxonomies. European Journal of Personality, 15, 425-448.

Pfeffer, J., \& Sutton, R. (2000). The knowing-doing gap: How smart companies turn knowledge into action. Boston: Harvard Business School Press.

Pillutla, M. M., \& Murnighan, J. K. (1996). Unfairness, anger, and spite: Emotional rejections of ultimatum offers. Organizational Behavior and Human Decision Processes, 68, 208-224.

Potworowski, G., Vath, R., \& Shah, P. (2006 June). Insights into teaching decision making from the learning sciences. Poster presented at teaching pre-conference at the Behavioral Decision Research in Management Conference, Santa Monica, CA.

Quigley, B., \& Tedeschi, J. (1996). Mediating effects of blame attributions on feelings of anger. Personality and Social Psychology Bulletin, 22, 1280-1288.

Rafaeli, A., \& Sutton, R. I. (1991). Emotional contrast strategies as means of social influence: Lessons from criminal interrogators and bill collectors. Academy of Management Journal, 34, 749-775.

Robinson, R. J., Lewicki, R. J., \& Donahue, E. M. (2000). Extending and testing a five factor model of ethical and unethical bargaining tactics: Introducing the SINS scale. Journal of Organizational Behavior, 21, 649-664.

Roseman, I. (1984). Cognitive determinants of emotion: A structural theory. Review of Personality \& Social Psychology, 5, 11-36.

Rosette, A. S. R., \& Kopelman, S. (2008). Good grief! Feelings of anxiety sour the economic benefits of first offers. Working Paper, Duke University. 
Rousseau, D. M. (2006). Is there such a thing as evidence-based management? Academy of Management Review, 31, 256-269.

Rousseau, D. M., \& McCarthy, S. (2007). Evidence-based management: Educating managers from an evidence-based perspective. Academy of Management Learning and Education, 6, 84-101.

Scherer, K. (1984). Emotion as a multicomponent process: A model and some cross-cultural data. Review of Personality \& Social Psychology, 5, 37-63.

Schwarz, N., \& Clore, G. L. (1996). Feelings and phenomenal experiences. In E. Higgins \& A. Kruglanski (Eds.), Social psychology: Handbook of basic principles (pp. 433-465). New York: Guilford Press.

Shell, R. G. (2007). Three schools of bargaining ethics. In R. J. Lewicki, B. Barry, \& D. M. Saunders (Eds.), Negotiation: Readings, exercises and cases (5th ed., pp. 230-235). Boston: McGraw-Hill.

Sinaceur, M., \& Neale, M. (2005). Not all threats are created equal: How implicitness and timing affect the effectiveness of threats in negotiations. Group Decision and Negotiation, 14, 63-85.

Sinaceur, M., \& Tiedens, L. Z. (2006). Get mad and get more than even: When and why anger expression is effective in negotiations. Journal of Experimental Social Psychology, 42, 314-322.

Smith, C., \& Ellsworth, P. (1985). Patterns of cognitive appraisal in emotion. Journal of Personality and Social Psychology, 48, 813-838.

Stanovich, K. E., \& West, R. F. (2000). Individual differences in reasoning: Implications for the rationality debate? Behavioral and Brain Sciences, 23, 645-665.

Thompson, L., \& DeHarpport, T. (1998). Relationships, goal incompatibility, and communal orientation in negotiations. Basic \& Applied Social Psychology, 20, 33-44.

Thompson, L., Valley, K., \& Kramer, R. (1995). The bittersweet feeling of success: An examination of social perception in negotiation. Journal of Experimental Social Psychology, 31, 467-492.

Ury, W. (1993). Getting past no: Negotiating your way from confrontation to cooperation. New York: Bantam Books.

Ury, W. L., Brett, J. M., \& Goldberg, S. B. (1988). Getting disputes resolved: Designing systems to cut the costs of conflict. San Francisco, CA: Jossey-Bass.

Van Kleef, G. A., De Dreu, C. K. W., \& Manstead, A. S. R. (2004a). The interpersonal effects of anger and happiness in negotiations. Journal of Personality and Social Psychology, 86, 57-76.

Van Kleef, G. A., De Dreu, C. K. W., \& Manstead, A. S. R. (2004b). The interpersonal effects of emotions in negotiations: A motivated information processing approach. Journal of Personality and Social Psychology, 87, 510-528.

Shirli Kopelman is an assistant professor of management and organization at the Ross School of Business at the University of Michigan. She received a $\mathrm{PhD}$ in management and organizations from the Kellogg School of Management at Northwestern University and has a BA in psychology from The Hebrew University of Jerusalem. Her research focuses on individual and group decision making in social dilemmas, factors promoting cooperation in interdependent intra- and inter-organizational contexts, strategic display of emotions, negotiation strategy, and cross-cultural differences in approaches to conflict management and resolution.

Georges Potworowski is a doctoral candidate in the combined program in education and psychology at the University of Michigan. He received a master's degree in applied 
cognitive science from the University of Toronto, and bachelor's degrees in philosophy and applied linguistics from Concordia University. His research centers on improving judgment and decision making, with a specific focus on indecisiveness, expert learning and practice change, evidence-based practice, and negotiation strategy. 